Texas A\&M University- San Antonio

Digital Commons@ Texas A\&M University-San Antonio

History Faculty Publications

College of Arts and Sciences

1998

\title{
Seriation, Superposition, and Interdigitation: a History of Americanist Graphic Depictions of Culture Change
}

R. L. Lyman

S. Wolverton

Michael J. O'Brien

Texas AઐM University-San Antonio, Mike.Obrien@tamusa.edu

Follow this and additional works at: https://digitalcommons.tamusa.edu/hist_faculty

Part of the Anthropology Commons

\section{Repository Citation}

Lyman, R. L.; Wolverton, S.; and O'Brien, Michael J., "Seriation, Superposition, and Interdigitation: a History of Americanist Graphic Depictions of Culture Change" (1998). History Faculty Publications. 20.

https://digitalcommons.tamusa.edu/hist_faculty/20

This Article is brought to you for free and open access by the College of Arts and Sciences at Digital Commons @ Texas A\&M University- San Antonio. It has been accepted for inclusion in History Faculty Publications by an authorized administrator of Digital Commons @ Texas A\&M University- San Antonio. For more information, please contact deirdre.mcdonald@tamusa.edu. 


\title{
SERIATION, SUPERPOSITION, AND INTERDIGITATION: A HISTORY OF AMERICANIST GRAPHIC DEPICTIONS OF CULTURE CHANGE
}

\author{
R. Lee Lyman, Steve Wolverton, and Michael J. O'Brien
}

\begin{abstract}
Histories of Americanist archaeology regularly confuse frequency seriation with a technique for measuring the passage of time based on superposition-percentage stratigraphy-and fail to mention interdigitation as an important component of some percentage-stratigraphic studies. Frequency seriation involves the arrangement of collections so that each artifact type displays a unimodal frequency distribution, but the direction of time's flow must be determined from independent evidence. Percentage stratigraphy plots the fluctuating frequencies of types, but the order of collections is based on their superposition, which in turn illustrates the direction of time's flow. Interdigitation involves the integration of sets of percentage-stratigraphy data from different horizontal proveniences under the rules that (1) the order of superposed collections cannot be reversed and (2) each type must display a unimodal frequency distribution. Ceramic stratigraphy is similar to occurrence seriation, as both focus on the presence-absence of types with limited temporal distributions-index fossils-but the former uses the superposed positions of types to indicate the direction of time's flow, whereas occurrence seriation does not.
\end{abstract}

Las historias de arqueología americanista regularmente confunden la frecuencia de seriación con una técnica para medir el paso del tiempo basada en la superposición-porcentaje estratigráfico-y con un éxito no alcanzado para aludir a la interdigitación como un componente importante en algunos estudios de porcentaje estratigráfico. La frecuencia de seriación implica el arreglo de colecciones para que cada tipo de artefacto despliegue una distribución de frecuencia unimodal; sin embargo, la dirección del paso del tiempo debe ser determinada a partir de la evidencia independiente. El porcentaje estratigráfico traza las frecuencias fluctuantes de los tipos, pero el orden de las colecciones está basado en su superposición-que a su vez ilustra la dirección del paso del tiempo. La interdigitación implica la integración de grupos de datos del porcentaje estratigráfico desde distintas procedencias horizontales bajo las reglas de que (a) el orden de las colecciones superpuestas no puede ser invertido y (b) que cada tipo debe desplegar una distribución unimodal. La estratigrafía cerámica es similar a la ocurrencia de seriación desde el momento en que ambos se enfocan en la presencia-ausencia de tipos con distibuciones temporales limitadas-fósiles de archivo-sin embargo, el primero usa las posiciones superpuestas de tipos para indicar la dirección del flujo temporal, mientras que la ocurrencia serial no lo hace.

$\mathrm{T}$ The culture-history paradigm constituted the first body of methods used by Americanist archaeologists of the twentieth century to derive meaning from the archaeological record (Binford 1968; Deetz 1970; Dunnell 1978, 1986; Gorenstein 1977; Lyman et al. 1997; Willey and Sabloff 1993). The founders of the paradigm saw as their initial—but certainly neither the only nor the final-goal the establishment of a chronology of archaeological phenomena. One innovative and distinctive method developed during the early years of the paradigm was seriation, although in later years it has been confused with a number of other chronological methods. Thus it is not surprising to find it defined as "the determination of the chronological sequence of styles, types, or assemblages of types (cultures) by any method or combination of methods. Stratigraphy may be employed, or the materials may be from surface sites" (Hester et al. 1975:272). Given such a definition, neither is it surprising to read that the "principle of seriation was allied to stratigraphy" (Willey and Sabloff 1993:96), or that James A. Ford used seriation in his work in the Southeast during the 1930s (Trigger 1989:200-202; Watson 1990:43; Willey and Sabloff 1993:113-114), or that A. V. Kidder (e.g., 1931:7) used seriation to construct a cultural chronology in the Southwest (Givens 1992:44). We also read that Nels Nelson "for the first time made a strict use of statistical

R. Lee Lyman, Steve Wolverton, and Michael J. O'Brien - Department of Anthropology, 107 Swallow Hall, University of Missouri, Columbia, MO 65211

American Antiquity, 63(2), 1998, pp. 239-261.

Copyright $(C)$ by the Society for American Archaeology 
methods developed in Europe, and reported this method in 1916" (McGregor 1965:42) and that this "statistical method" of studying fluctuating frequencies of types was introduced to the Americas as a result of the influence of W. M. F. Petrie (Browman and Givens 1996:83).

Close reading of the Americanist archaeological literature that appeared between 1910 and 1940, however, indicates that such statements result from the conflation of the particulars of analytical techniques developed and used by those who founded the culture-historical approach and their failure to explicitly define and distinguish among distinct techniques. In short, sloppy use of terms has resulted in misunderstanding the history of seriation, the various techniques by which it may be implemented, and its relation to the use of artifacts contained in superposed sediments for chronological purposes. We attempt here to clear away this misunderstanding by providing explicit definitions of key terms based on how various analytical techniques were first used and by reviewing the history of various techniques employed to order artifact collections into what are inferred to be chronological sequences.

Today, there are a number of statistical and computer-assisted techniques for seriating collections of artifacts (see Cowgill 1972 and Marquardt 1978 and references therein), although these date from the mid-1960s. Prior to that time, two techniques founded on the frequencies of types were used to sort assemblages into what was inferred to be chronological order. One involved the use of tables of numbers, and the other involved the use of graphs. Confusion arose because sometimes the superposed positions of collections were used to create the order and other times they were not. Also confusing matters was that graphs sometimes summarized empirical data, and at other times they reflected a researcher's interpretations. In this paper we examine the historical development of the various analytical techniques that are often categorized as seriation, paying close attention to graphs having similar appearances but constructed on different bases. Ultimately, we show how the use of numbers to sort collections evolved into the use of graphs, and we trace much of the modern terminological confusion to the similarities of graphs constructed using distinctly different protocols.

\section{Seriation}

Seriation-arrangement in a series; position according to some law of a series (Webster's New Twentieth Century Dictionary, unabridged 2nd ed., 1974, p. 1,656)

As far as we have been able to discover, Edward Sapir (1916:13) was the first American anthropologist to use the term "seriation" when he indicated that "cultural seriation" was a "method ... often used to reconstruct historical sequences from the purely descriptive material of cultural anthropology." Importantly, he also stated that (1) the "tacit assumption involved in this method is that human development has normally proceeded from the simple or unelaborated to the complex," (2) "evidence derived from seriation . . . fits far better with the evolutionary than with the strictly historical method of interpreting culture," and (3) this method "is probably at its best in the construction of culture sequences of simple-to-complex type in the domain of the history of artifacts and industrial processes, particularly where the constructions are confined to a single tribe or to a geographically restricted area" (Sapir 1916:13-15). Thus, cultural seriation was founded in the presumption of cultural evolution in terms of Lewis Henry Morgan (e.g., 1877). Seriation as an analytical technique can be based on this presumed course of cultural change and, in some instances, was, such as Kidder's (1915) suspicion that glazed pottery was more recent than unglazed pottery because of the greater technological sophistication of the former. But, as we will see, seriation need not be based on such an assumption.

Leslie Spier (1917a:281, 1917b:281) was, apparently, the first American archaeologist to use the term "seriation," and he did not reference Sapir's paper. Spier used the term to refer to the work of A. V. Kidder (1915), characterizing it as "the hypothetical seriation of several pottery techniques" (Spier 1917a:252). Spier (1917a:252, 281) also used the term to refer to the work of his mentor, A. L. Kroeber (1916a, 1916b), although he characterized the latter's work as "the hypothetical ranking of surface finds and the observation of concurrent variations." That the characterizations differed suggests the analyses performed by Kidder and Kroeber differed. In fact, Kidder's $(1915,1917)$ "seriations" were of a decidedly different sort than Kroeber's. Spier's (1917a:252) crediting of "Kidder 
for the concept of seriation [and] Kroeber for ranking and concurrent variation" should have precluded any confusion of two distinct analytical techniques, but this was not the case. Repetition 50 years later (Taylor 1963:379) of Spier's notations, for example, failed to explicitly distinguish between the two techniques and thus exacerbated the confusion. Other discussions of seriation (e.g., Rouse 1967; Rowe 1961), while distinguishing between evolutionary, or developmental, seriationKidder's version-and other seriation techniques, have also failed to clarify matters.

Although recognized for his use of what later became known as frequency seriation when awarded the Viking Fund Medal, Spier, like his contemporaries, did not explicitly define "seriation" in his seminal papers (Spier 1917a, 1917b). He later characterized seriation as a method in which the "remains of a stylistic variable (such as pottery) occurring in varying proportions in a series of sites are ranged [ordered], by some auxiliary suggestion, according to the seriation [ordering] of one element (one pottery type)" (Spier 1931:283). Although this was in fact what Kroeber (1916a, 1916b) had done, others who later used frequency seriation seem to have ordered their collections on the basis of multiple types (e.g., Kniffen 1938). The "auxiliary suggestion" to which Spier (1931) referred-earlier characterized by him as a "principle for the seriation of the data" (Spier 1917a:281)—anticipated that the relative frequencies of pottery types through time would exhibit smooth changes that approximated a normal curve. This suggestion is the "popularity principle" (Lyman et al. 1997:43) and to this day has served as the underlying guide - the axiom-to performing a frequency seriation - that is, ordering collections of artifacts using relative frequencies of artifact types (e.g., Dunnell 1970; Rouse 1967; Teltser 1995).

The creation of terminological confusion cannot be laid solely at Spier's feet. Kidder (1919:298) characterized Spier's (1917a, 1918, 1919) work as involving (1) the "seriation" of artifact collections on the basis of a single type of artifact and (2) subsequent testing of the validity of the final arrangement on the basis of "concurrent variations in the accompanying wares." In other words, Kidder referred to Spier's "hypothetical ranking of surface finds and the observation of concurrent variations" as "seriation." Analytically, Spier (1917a, 1917b) was simply mimicking what Kroeber (1916a, 1916b) had done-ordering collections based on frequencies of types-plus adding an important new step. Yet Kroeber did not originally refer to his particular analytical technique as "seriation." Kroeber (1925a:406) later referred to some of his own seriations as "nonstratigraphical comparison of the frequency of several types of ceramic decoration"; these are correctly categorized as frequency seriations. Definitions of seriation offered over the past half century, however, tend not to echo Spier's and Kroeber's usage of the term to indicate ordering collections of artifacts based solely on the concurrent variations in the frequencies of types.

Kroeber (1927:626) also spoke of Uhle's (1902, 1903) "stylistic seriation" of Peruvian material. Uhle (1902:754) asserted that the "method applied by Flinders Petrie in Egypt to prove the succession of styles by gradually changing character of the contents of graves differing in age has given remarkable results." Petrie (e.g., 1899, 1901) called what he did "sequence dating," a term repeated by few Americanists (e.g., Heizer 1959:375). Praetzellis (1993:76) states that "Seriation was developed by Flinders Petrie for the analysis of excavated Egyptian ceramics, and apparently brought to North America by Max Uhle who introduced it to Alfred Kroeber." This is a common misconception (e.g., Browman and Givens 1996); Trigger (1989:202) is correct when he notes that "although Kroeber may have learned the basic principles of typology and seriation from Boas and known of Petrie's work, his technique of seriation was not based on the same principles as Petrie's." Petrie $(1899,1901)$ first seriated pottery on the basis of its stylistic or formal similarity. Only after establishing an order did he examine the frequencies of pottery types. He arranged pottery in a "series of development or degradation of form." The resulting arrangement was "of the highest value. It enables a long period to be arranged in approximate order, and serves as a scale for noting the rise or disappearance of other types" (Petrie 1899:297). We have elsewhere termed this ordering technique "phyletic seriation" (Lyman et al. 1997:54); Rowe (1961) referred to it as "similiary seriation," and Rouse (1967) termed it "developmental seriation." 


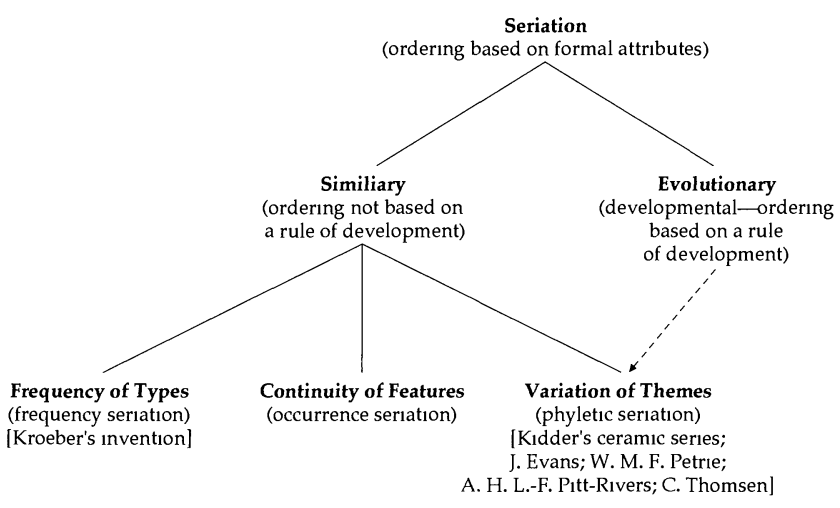

Figure 1. A taxonomy of seriation techniques. Seriation comprises techniques of ordering based on formal similarities. Evolutionary seriation-ordering based on an assumed rule of development-can inform any of the similiary techniques, but it most often informs phyletic seriation.

Petrie's use of phyletic seriation had precedence in the work of John Evans (1850) and A. L. Pitt-Rivers (1875). Willey and Sabloff (1993:113) suggest that Kroeber popularized and "made explicit" the notion of phyletic seriation: "This was done in a series of papers in the 1920s, in which Kroeber shifted from the potsherd frequency seriation he had pioneered in the Southwest to a grave-lot and stylistic approach that could be adapted to the Uhle [Peruvian] collections." While it is true that Kroeber and his students did use phyletic seriation (e.g., Kroeber and Strong 1924; Strong 1925), Kidder's $(1915,1917)$ work already had established a significant precedence for such a principle of ordering in archaeology; the principle already existed in anthropology generally (e.g., Sapir 1916; Wissler 1916b). Within Americanist archaeology, the basic notion of phyletic seriation was later manifest in the concept of a (ceramic) "series," a term first used by Kidder (1917:370) and later adopted by Colton and Hargrave (1937:2-3) and Wheat et al. (1958).

What is important to realize, then, is that between about 1915 and 1935, several different terms were being applied to the same analytical technique; simultaneously, the same or a similar term was being applied to distinct techniques (Figure 1). We like Rowe's (1961:326) definition of seriation, which is "the arrangement of archaeological materials in a presumed chronological order on the basis of some logical principle other than superposition .... The logical order on which the seriation is based is found in the combi- nations of features of style or inventory which characterize the units, rather than in the external relationships of the units themselves" (emphasis added). We prefer this definition precisely because it underscores that the ordering is based on formal attributes of the seriated materials - that is, it is based on intrinsic characteristics of the artifacts and not on superposition. Rouse (1967:156) appears to agree but in our view fails to emphasize this point sufficiently. Dunnell (1970:310), too, seems to agree that the ordering produced during seriation is based solely on formal properties of the seriated materials without reference to their stratigraphic positions or other independent chronometric data, noting that arrangements resulting from seriation "are strictly formal orders.... They must be inferred to be chronologies." Similarly, Braun (1985:509) states that "archaeological seriation asks the question, 'Can we order this set of objects or places according to their relative ages, based on their physical characteristics?" Frequency seriation involves ordering collections of presumably historical types such that each type has a continuous distribution and a unimodal frequency distribution. The ordering is based solely on type frequencies.

Whether a correct order in fact measures the passage of time is an entirely different matter-a point recognized by both Spier (1917a, 1917b) and Kroeber (1916a:20), the latter stating that the proof that his frequency seriation monitored the passage of time was "in the spade." This was one reason why Kidder (1916) went to Pecos Puebloto test the sequence he had derived using phyletic seriation (Kidder 1915) and to confirm and add to Nelson's sequence. The stratigraphic revolution so often spoken of (e.g., Browman and Givens 1996; Willey 1968; Willey and Sabloff 1993) thus used the principle of superposition as a chronological tool to confirm rather than, as is typically claimed, to discover the passage of time (for extended discussion, see Lyman and O'Brien 1998 and Lyman et al. 1997).

\section{Superposition}

Before the end of the nineteenth century, 
Americanist archaeologists in general believed that artifacts in lower or deeper strata were older than those in higher or shallower strata (Lyman and O'Brien 1998). This belief derived from the notion of superposition, defined by Rowe (1961:324) as follows: "In any pile of deposition units in which the top and bottom of the pile can be identified, the order of succession from bottom to top gives the order of deposition." What most Americanist archaeologists failed to realize was that "the principle of superposition offers absolute certainty only of the sequence of deposition units at a particular site" (Rowe 1961:326). There was no assurance that the relative ages of artifacts contained in strata were accurately reflected by the order in which the containing strata were deposited. Because of their artifact-centric view, archaeologists eventually developed notions such as "reversed stratigraphy" and "mixed strata" to account for cases where suspected relative ages were out of order (Lyman et al. 1997:74-78; Stein 1990). Early in the twentieth century, however, such notions were not well developed, and the principle of superposition was used virtually without question to confirm suspected or to determine unknown chronologies of artifacts.

In the work that led to his first use of the term "seriation," Spier (1917a, 1917b) not only used frequency seriation to order collections, but he also used an analytical technique later termed "percentage stratigraphy" (Willey 1939) to confirm that the results of his and Kroeber's (1916a, 1916b) frequency seriations monitored the passage of time. That is, he tested the notion that the unimodal frequency distribution of types-the popularity principle-was a valid rule for ordering assemblages. If artifact-type frequencies fluctuated unimodally through vertical space-which, it was thought, measured time, given the principle of superposition-then the rule was valid (Spier 1916; Wissler 1916a). Because of Spier's simultaneous use of two unique techniques for ordering artifacts without clear terminological distinction, they were confused with one another in later literature and, we believe, contributed to the misconception that there was a "stratigraphic revolution" (Lyman and O’Brien 1998).

Importantly, frequency seriation does not employ superposition to arrange collections; rather, it focuses on the frequencies of types and employs only the popularity principle-Kroeber and Spier's concurrent variations in frequenciesto order collections. "Percentage stratigraphy" uses the superposed positions of artifact assemblages to establish their order and arrays the relative frequencies of types against their vertical positions. Thus, Spier (1917a, 1917b) was able to test the results of his frequency seriations not only in terms of the correctness of the ordering, but also in terms of whether or not they actually measured time, as indicated by the vertically superposed spatial positions of assemblages. Kidder and Kidder (1917) used percentage stratigraphy for virtually the same purpose.

We prefer the term "percentage stratigraphy" to describe what Spier (and Kidder and Kidder) did, although the term apparently was first used by Gordon Willey (1939) two decades after Spier's work. Spier (1931:281) indicates that the method he used in 1916 (Spier 1917a, 1917b) was a "combination of Kroeber's method [frequency seriation of surface samples] with Nelson's," the latter being, according to Spier (1917b:281), the "stratigraphic observation of refuse deposits." McGregor (1941:54) later described the percentage-stratigraphy technique - what he called a "combined statistical-stratigraphic method"-as involving (1) classifying sherds, (2) tallying each type's frequency from each area of excavation "and tabulat[ing the] relative abundance of occurrence [of each type] on a large chart," and (3) comparing different areas of excavation to determine where a "specific type was most abundant in relation to all the others, and in this manner it is possible to reconstruct the order of building of the [site]." Although Spier (1917a:253) noted that Nelson demonstrated the "practicability of obtaining samples of sherds at random from the successive levels of the [refuse] heap, and by determining the proportions of the constituent wares at each level indicat[ed] the course of the pottery art," Nelson (1916) did not calculate the relative or proportional abundances of the pottery types he discussed. Rather, he presented the absolute abundances of each type; why he did so is discussed elsewhere (Lyman and O'Brien 1998; Lyman et al. 1997).

In short, percentage stratigraphy involves placing the proportional abundances of artifact types per vertically defined assemblage against each 
assemblage's vertical provenience within a single site. Unlike frequency seriation, which orders assemblages only on the basis of the popularity principle, percentage stratigraphy uses the vertical provenience of collections as the basis of ordering, with the expectation that the ordered frequencies will display a unimodal distribution (the popularity principle). After Spier's (1917a, 1917b, 1918, 1919) work, numerous individuals used percentage stratigraphy both to measure time and to determine if their types, in fact, measured time; finding that the fluctuating frequencies of individual types did not always match from excavation to excavation is what ultimately led to notions of reversed and mixed stratigraphy (e.g., Amsden 1931; Dutton 1938; Ford 1935; Hawley 1934; Martin 1936; Nelson 1920; Schmidt 1928). This technique for ordering collections was variously referred to as the "stratigraphic observation of refuse heaps" (Spier 1917a:252), "pottery stratification" (Hawley 1934:62), "refuse stratigraphy" (Reiter 1938:100), "vertical stratigraphy" (Ford 1936:103), "stratigraphic tests" (Martin 1936:104), and "stratigraphic investigation" (Schmidt 1928:256).

Given the set of terms used to refer to what we are calling percentage stratigraphy, the term "ceramic stratigraphy" may seem redundant. This term was first used-without definition-by Nelson (1919:133) to characterize his work at Pueblo San Cristobal in north-central New Mexico (Nelson 1916) — work that we categorize as the predecessor of percentage stratigraphy because Nelson examined fluctuations in the absolute frequencies of types. Drucker (1943b), too, used the term "ceramic stratigraphy" without definition; he examined shifts in absolute and relative frequencies of ceramic types through a vertical column of sediment, and thus his work is better characterized as percentage stratigraphy. While Nelson (1919) did not define "ceramic stratigraphy," Willey's (1939) later use of this term-again without explicit definition-indicates that the passage of time can be detected by monitoring the relative vertical positions of different pottery types within a site. It was this technique that Manuel Gamio (1913), in fact, used to confirm the suspected sequence of pottery in the Valley of Mexico; Holmes (1885) had done the same thing 25 years earlier.

Ceramic stratigraphy (somewhat of a misnomer, since any kind of artifact ostensibly could be used) is similar to what is elsewhere termed "occurrence seriation" (Dunnell 1970; Rouse 1967) because it focuses, unlike percentage stratigraphy or frequency seriation, on the presence-absence of temporally sensitive types rather than on their fluctuating frequencies. But as with percentage stratigraphy, ceramic stratigraphy derives its ordering of types from the relative vertical (superposed) positions of types in a column of sediment. Unlike occurrence seriation, ceramic stratigraphy does not sort collections so that types display a continuous occurrence across multiple collections, although this is, implicitly, the expected result. The discontinuous occurrence of a type through a vertical sequence of depositional units might indicate that the type is not temporally sensitive, the samples are inadequate, or the strata are "mixed" or "reversed."

\section{Interdigitation}

As first used by Willey (1949), "interdigitation" denotes the integration of percentage-stratigraphy data from several distinct excavation units and/or sites into a summary graph of bars, the widths of which denote the proportional frequency of a type (Figure 2). Bars are each given a unique shading or stippling to denote horizontal recovery provenience-usually the site-and are centered in columns so that each column represents a distinct type. Although in operation interdigitation is similar to frequency seriation, the one thing that cannot be violated is the vertical order of the site-specific bars. Otherwise, the principle of ordering is the same as that which guides frequency seriation: arrange the bars so that the final ordering within each column approximates as closely as possible a normal frequency distribution.

Not everyone was clear on how actually to interdigitate percentage-stratigraphy data, but they seem to have understood the basic notion. Paul Martin (1936:108), for example, employed percentage-stratigraphy data from various southwestern areas, and although he attempted to interdigitate these data in order "to work out a correlation between building periods and pottery col-

Figure 2. (opposite) Gordon R. Willey's interdigitated percentage-stratigraphy data. Note that each bar's shading is unique to its horizontal recovery provenience as indicated in the left column, and the width of each bar reflects the relative abundance of a type (after Willey 1949, Figure 14). 


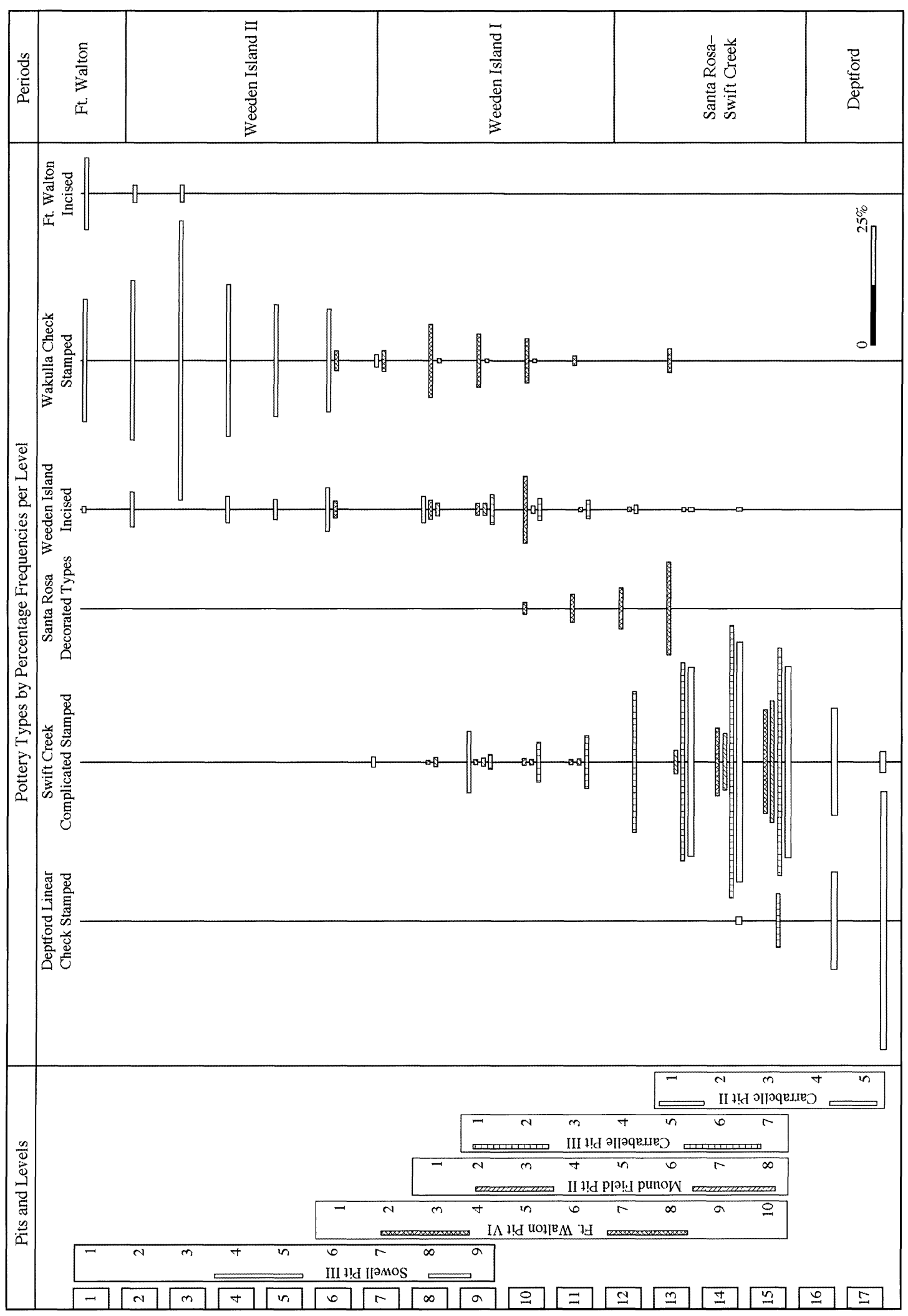


lected from floors," he had little success. Ford and Willey (1940:136) appear to have published one of the earliest approximations of an interdigitation. They sorted two Louisiana sites, each representing what we would today call a "single component," and merely stacked one on top of the other. They did not refer to their effort as interdigitation, but their graph foretold of things to come (O'Brien and Lyman 1998). Drucker (1943a:101, Figure 101) integrated ceramic-frequency data from four "stratigraphic trenches" excavated in Tres Zapotes in Veracruz, Mexico, but his summary graph shows only the relative positions of the arbitrary levels excavated in each trench rather than type frequencies. Given that he presented the percentage-stratigraphy data for each trench in tabular form (Drucker 1943a:91-99), one could construct a bar graph of interdigitated data if desired.

Probably the best-known instance of interdigitation is in Ford's (1949) study of ceramics from Virú Valley, Peru, although Willey (1953:10) referred to Ford's efforts as "horizontal stratigraphy or seriation." This was an unfortunate usage, as it no doubt fed the myth that Ford used frequency seriation throughout his career when in fact he rarely used it. It also was unfortunate that Phillips (1951:109) referred to what we are calling interdigitation as "the method of combining two or more stratigraphic cuts on the same site in a single interpolated seriation." By this wording, "interpolated seriation" is synonymous with interdigitation, thus adding to the confusion.

\section{Summary}

The earliest arrangements of artifact types meant to denote the passage of time were varied in appearance and in the analytical technique used to generate them. Gamio (1913) used what we have termed "ceramic stratigraphy," Nelson (1916) used a precursor of percentage stratigraphy, Kidder variously used percentage stratigraphy (Kidder and Kidder 1917) and phyletic seriation (Kidder 1915, 1917), Kroeber (1916a, 1916b) used frequency seriation, and Spier (1917a, 1917b) used both frequency seriation and percentage stratigraphy. Ford's (1936) analysis, although today characterized either as "seriation" (Watson 1990) or as "occurrence similiary seriation" (Willey and Sabloff 1993:115), was not, in fact, a seriation, nor was it interdigitation. Ford knew the sequence of key (what he termed "marker") types based on percentage-stratigraphy data he had generated earlier (Ford 1935), and he used a three-period sequence of marker types to merely sort surface collections into one of the three periods (O'Brien and Lyman 1998). He did not order the surface assemblages within each period relative to each other; instead, he merely listed which surface assemblages fell within each period as denoted by included marker types. As he himself remarked, "In this study the desired results are not the ages of individual sites, but the relative ages of the different schools of ceramic art" (Ford 1936:10); each "school of ceramic art" or "decoration complex" (Ford 1936, 1938) was denoted by a certain set of marker types.

We suspect the sorts of terminological ambiguities represented by Spier's use of the term "seriation" to denote two distinct analytical techniques and our inability to categorize Ford's early work characterize the innovative periods of any discipline. Attempts by several individuals working somewhat independently to solve an analytical problem result in multiple innovative techniques that are in some ways similar and in other ways distinct. People try to emulate one or more of the innovations without completely understanding them, which in turn produces mutations-that is, further innovation. To enhance communication, names are assigned to various innovative techniques, but no one really knows intimately what goes into a particular individual's technique or which term best matches which technique. Confusion results and is perpetuated if no one stops to take stock and tidy up a bit.

\section{Techniques for Studying Changes in Artifact Frequency}

We attempted above to clean up some of the ambiguities, but more remain. We focus the remainder of our discussion on the analytical use of type frequencies to measure time, paying particular attention to various graphic techniques.

\section{Beginning with Numbers}

Nelson (1916) presented a table of numbers representing the absolute abundances of pottery types within individual vertical excavation units. Kroeber (1916a, 1916b) and Spier (1917a) both presented their data in the form of tables of numbers representing both the absolute and the rela- 


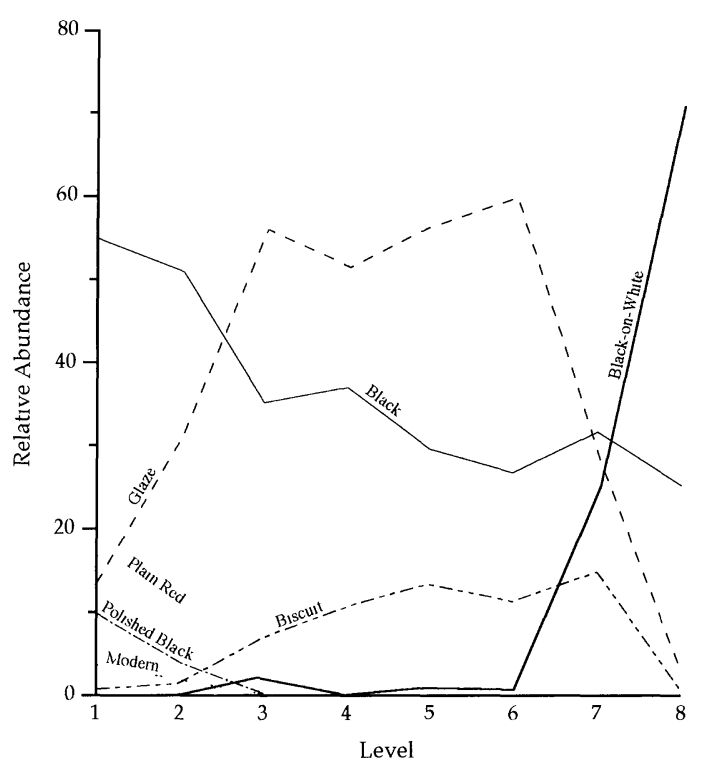

Figure 3. An example of a broken-stick graph showing the fluctuating frequencies of types over vertical space (inferred to represent time) (after Kidder and Kidder 1917:344, Figure 54, cut $X$ ).

tive, or proportional, frequencies of their various pottery types. This was a reasonable strategy, but when numerous types and many different collections were involved, seeing the unimodal frequency distributions that were supposed to reflect the popularity principle became difficult. Spier (1917a) calculated a correlation coefficient to show that the frequencies of his types shifted as they should relative to one another, and while this helped, we suspect that the general lack of statisti- cal sophistication of the discipline significantly reduced the utility of the strategy.

Kidder (1919:301) noted Spier's (1917a) work as "good method" and "fundamental." Perhaps not surprisingly, then, Kidder and Kidder (1917) published tables of numbers in which they presented both the absolute and the relative frequency of pottery types arranged against vertical recovery provenience. They then plotted the relative frequencies of these seven types against vertical provenience in a broken-stick graph, an example of which is shown in Figure 3. The distributions of some of the types in this and other graphs presented by Kidder and Kidder seemed to approximate the popularity principle, but other types did not clearly show unimodal frequency distributions, either because the individual types did not display such distributions or the graph was too busy to allow ready perception of such a distribution. Kidder (e.g., 1924, 1936) later abandoned the study of fluctuating frequencies of artifact types (Lyman et al. 1997).

Tables of numbers provided the raw data, but they were difficult to interpret: One had to track each column of numbers, which represented a type or style, to determine if that artifact category displayed a unimodal frequency distribution. If the table summarized data for a dozen or more types and a similar number of collections, reading the table was difficult. Take, for example, the first true frequency seriation to be published after 1920 of which we are aware-Fred Kniffen's (1938) seri-

Table 1. Fred B. Kniffen's (1938) Frequency Seriation of Sites in Iberville Parish, Louisiana.

\begin{tabular}{|c|c|c|c|c|c|c|c|c|c|c|c|c|}
\hline \multirow[b]{2}{*}{ Site } & \multicolumn{2}{|c|}{ Natchez } & \multicolumn{2}{|c|}{ Tunica } & \multirow{2}{*}{$\frac{\text { Caddo }}{\text { OT }}$} & \multicolumn{2}{|c|}{$\begin{array}{l}\text { Bayou } \\
\text { Cutler } \\
\end{array}$} & \multirow{2}{*}{$\begin{array}{c}\text { Coles } \\
\text { Creek }\end{array}$} & \multicolumn{2}{|c|}{ Deasonville } & \multirow{2}{*}{$\frac{\text { Marksville }}{\mathrm{M}}$} & \multirow[b]{2}{*}{ Unrelated } \\
\hline & $\mathrm{M}$ & OT & $\mathrm{M}$ & OT & & M & OT & & $\mathrm{M}$ & OT & & \\
\hline 1 & 5 & 29 & 9 & 6 & 7 & & 1 & & & & 1 & 46 \\
\hline 2 & 19 & 14 & 4 & 13 & 10 & & 8 & 1 & 2 & 4 & & 28 \\
\hline 3 & 6 & 11 & & & 3 & 20 & & & & & & 61 \\
\hline 4 & & & 2 & 9 & 10 & 34 & 36 & 4 & & 2 & & 4 \\
\hline 5 & 11 & & & & 3 & 72 & 10 & & & & & 9 \\
\hline 6 & 1 & & 1 & & 1 & 82 & 5 & & & & & 12 \\
\hline 7 & & & & & & 84 & 11 & 3 & & & & \\
\hline 8 & & & & & & 86 & 8 & 2 & 1 & & & 3 \\
\hline 9 & & & & & & 86 & 8 & 2 & & & & 5 \\
\hline 10 & & & & & & 66 & 15 & 1 & 2 & & 2 & 13 \\
\hline 11 & & & & & 4 & 33 & 10 & 15 & 2 & 2 & 17 & 17 \\
\hline 12 & & & & & & 27 & 40 & & & & 20 & 14 \\
\hline
\end{tabular}

Note: Natchez, Tunica, and Caddo sherd complexes date to the historical period; the prehistoric complexes are arranged in order from Bayou Cutler (most recent) to Marksville (oldest). Note that relative frequencies of sherds represented at each site do not necessarily total 100 percent. M designates marker type(s); OT designates other types. 


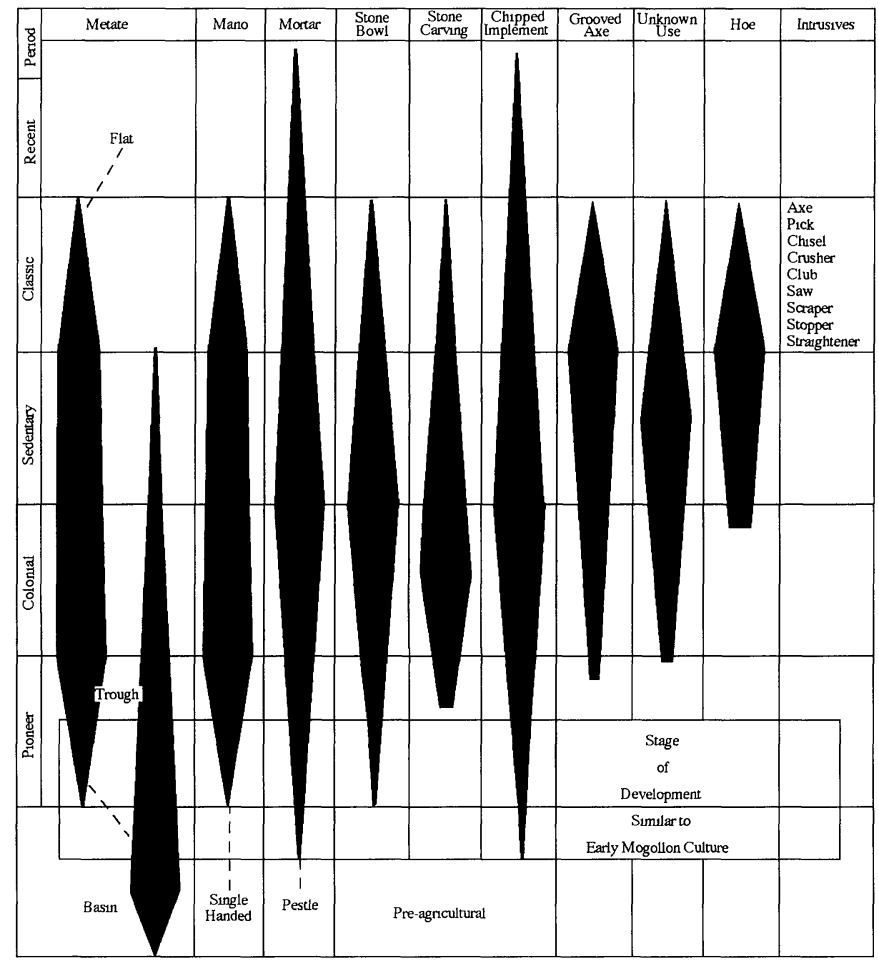

Figure 4. E. B. Sayles's diamond graph. Note that the sum of diamond widths varies between horizontal positions. This graph represents Sayles's interpretation of the history of the popularity of the various artifact categories (after Sayles 1937:118, Figure 48).

ation of 12 sites in Iberville Parish, Louisiana. Kniffen (1938:200) presented his seriation, without using the term, in tabular form, replicated here as Table 1 . This is a particularly complex example because it represents not only a frequency seriation but also one of Ford's methods of arranging collections in a temporal order as of 1937-1938. Kniffen (1938:199) indicates the "analysis is based on Ford's criteria" but does not elaborate. The table contains frequency data for what Ford (e.g., $1935,1936,1938)$ called (1) "marker types," or what we would term "index fossils" (Lyman et al. 1997), (2) "other than marker" types, which were characteristic of a "pottery complex" (Ford 1935, 1936, 1938), and (3) "unrelated," or noncharacteristic, types. Visual inspection of Table 1 suggests the arrangement was based on ordering the Caddo marker type so that it displayed a unimodal frequency distribution, with the exception that the temporally earlier Marksville marker type took precedence when it was present. Other type frequencies merely tagged along and thus typically do not display unimodal frequency distributions.
Whatever the particulars of procedure followed to produce the arrangement in Table 1, what is important to note here is that it is difficult to see unimodal frequency distributions of individual types simultaneously.

\section{The Use of Graphs}

Kidder and Kidder's (1917) broken-stick graphs were mimicked by some (e.g., Amsden 1931; Collier and Murra 1943; Martin 1936; Reiter 1938; Schmidt 1928), while others continued to present tables of numbers to demonstrate the popularity principle at work (e.g., Kroeber and Strong 1924; Strong 1925). Other researchers tried different graphic techniques in the 1930s to illustrate percentage-stratigraphy data; some of these, such as Dutton's (1938:90) confusing bar graphs and Nesbitt's (1938:85) pie diagrams (one per vertically superposed unit), are extremely difficult to read. Many of the graphs generated by frequency seriation and percentage stratigraphy were, however, so similar in appearance that confusion could have been predicted. Such confusion was exacer- 


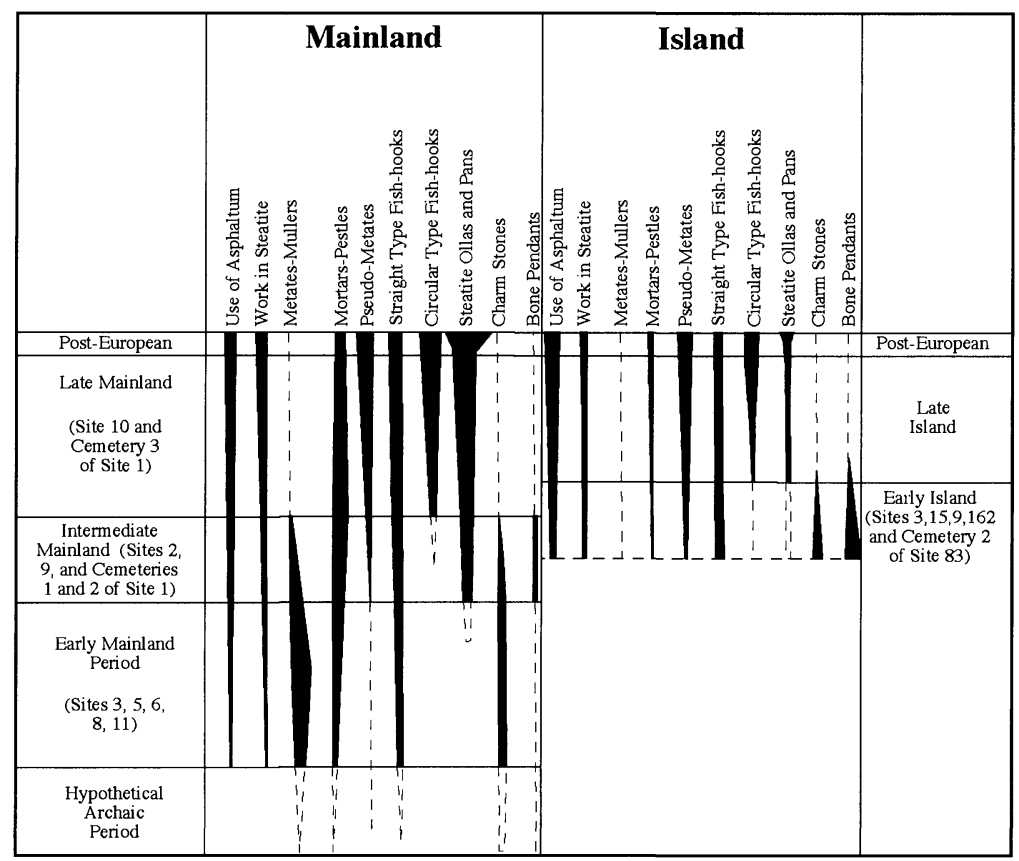

Figure 5. Ronald Olson's diamond graph, which he labeled “Reconstruction of prehistoric cultural changes.” The bars do not sum consistently to the same width between horizontal positions, and the graph illustrates Olson's interpretation of the popularity of the various types (after Olson 1930:21, Figure 3).

bated when Ford (1952b:323) remarked that one of the styles of graph he used was formally identical to a "developmental chart which E. B. Sayles [1937] used to show the history of utilitarian stone artifacts in Hohokam. Sayles, in turn, may have adapted this graph style from paleontology." In a footnote associated with this statement, Ford (1952b:323, Footnote 5) characterized his own development of the graphic technique as a personally "slow and painful process of crystallization" beginning in 1935. Ford began with percentage stratigraphy (e.g., Ford 1935) and stuck with it whenever possible, using frequency seriation only when geologically superposed collections were unavailable (e.g., Ford 1949, 1951, 1952a, 1952b; Phillips et al. 1951). But Ford was not always explicitly clear about which analytical technique he was using (O'Brien and Lyman 1998). Further, graphs had already been used to illustrate fluctuating frequencies of types through time, and these efforts probably added to the confusion.

Initially, two types of graphs were developed independently - diamond graphs and bar graphsbut neither was founded in frequency seriation. E. B. Sayles's (1937:118) developmental chart
(Figure 4) - a diamond graph-illustrates the history of types of stone tools recovered from the Hohokam site of Snaketown in Arizona. It decidedly is not a frequency seriation, although it has the general appearance of one; neither is it a graph depicting percentage stratigraphy. Rather, it demonstrates Sayles's inference of the history of the graphed artifact categories. Five facts make this clear. First, the graph was constructed after the chronology of periods had been established on the basis of Haury's (1937) studies of superposed ceramics. Second, the graphed categories are not stylistic or temporal types but instead are functional, technological, or morphological (descriptive) types. This does not mean they will not monitor the passage of time, but it certainly reduces the probability that they will display unimodal frequency distributions. As Kroeber (1919:239) had indicated nearly 20 years earlier, stylistic variations of an artifact category do not "vary in purpose," whereas other kinds of variation might. Third, the width of the diamonds at any particular horizontal position is meant to denote the popularity of particular artifact categories, but the sum of those widths is never consistently the same 
from one horizontal position to the next. Fourth, Sayles (1937:113) had no data from Snaketown for the time period before his "Pioneer" period, nor did he have data for his "Recent" time period, yet both are included in the graph. Finally, Sayles presented in tabular form the frequencies of items in the artifact categories he graphed, although the categories in his table (Sayles 1937:113) do not match precisely those he graphed.

Sayles (1937) cited no references that might have served as an inspiration for his graphic technique. Perhaps he derived the notion from a similar graph published earlier by Ronald Olson (1930), who earned his B.A. and M.A. degrees under the advisorship of Leslie Spier at the University of Washington in 1925 and 1926 and then attended the University of CaliforniaBerkeley from 1926 to 1929, working under Kroeber's tutelage (Drucker 1981; Stewart 1980). $\mathrm{He}$ was, therefore, trained in archaeological method by two of the innovators of frequency seriation and percentage stratigraphy. The graph he published in 1930 - reproduced here as Figure 5is the earliest graph of this form of which we are aware. Before this, only broken-stick graphs had been published to illustrate the history of the popularity of artifact types. Olson, however, cited no references as sources of inspiration for the form of graph he presented, but it is not difficult to surmise that his advisors had a hand in this innovation. Plog (1973:191) referred to a graph of this form as a "seriogram," but we suspect he meant any form of graph that shows the increase and decrease of a type's frequency.

Olson's graph carries the caption "Reconstruction of prehistoric cultural changes, Chumash area." It is not a frequency seriation for the same reasons that Sayles's is not. First, in both cases the basic chronology was known before the graph was produced. Second, the artifact categories are general functional or descriptive types rather than styles, and this reduces the chance that they will monitor the passage of time by displaying unimodal frequency distributions across vertical geological space. Third, the width of the diamond-like figures at any particular horizontal position in the graph is meant to denote the popularity or frequency of a particular artifact category, but the sum of those widths is never consistently the same from one horizontal position to the next. Olson presented only absolute abundances in his data tables, albeit corrected for differences in excavated volumes, and apparently did not calculate relative abundances.

Thus, Olson's graph, like Sayles's, is an interpretation of what Olson believed the popularity history of the graphed types to be. The graph indicates, Olson (1930:20-21) said, that some artifact categories "passed out of vogue" and others were "developed," there "are no indications of sudden or major shifts in pattern of culture," and there "is long adherence to primitive uniformity in the few objects needed to secure a livelihood." Such interpretations clearly were founded on the notion of the popularity principle, but strangely, here they were applied to functional types, whereas the principle initially had been coined to account for stylistic types. However, even Kroeber (e.g., 1925b) himself regularly confused the two.

In his classic Prehistory in Haiti: A Study in Method, Rouse (1939:85-87) graphed the "temporal distributions" of types and the fluctuating frequencies of pottery modes (that is, attributes) through time using diamond graphs. He stated that he used "the method called 'seriation' by Spier" to construct a "hypothetical sequence of sites" that was then "tested by means of a . . combination of both 'seriation' and 'stratigraphy,' to use Spier's terms" (Rouse 1939:28), but in fact, seriation was only a small part of what Rouse did. Rouse first sorted sites into two periods on the assumption that those with pottery were later than those without pottery. Then, he used the direct historical approach to sort the sites with pottery into a sequence of two periods, placing sites with pottery most like that described historically in the most recent group and sites with pottery less like that historically documented in a middle-period group. He then had three periods. Third, he used the relative abundance of a single, presumably late type of pottery to order sites within the middle period, based on the assumption that progressively older sites would have proportionately less and less of that type. This gave him four periods. Finally, on the basis of the relative frequency of particular modes, he ordered two sites in the middle period (of the three with pottery) that otherwise seemed contemporaneous. The result was a six-period sequence, and Rouse (1939:75) was explicit that these were "arbitrarily defined," noting that the 


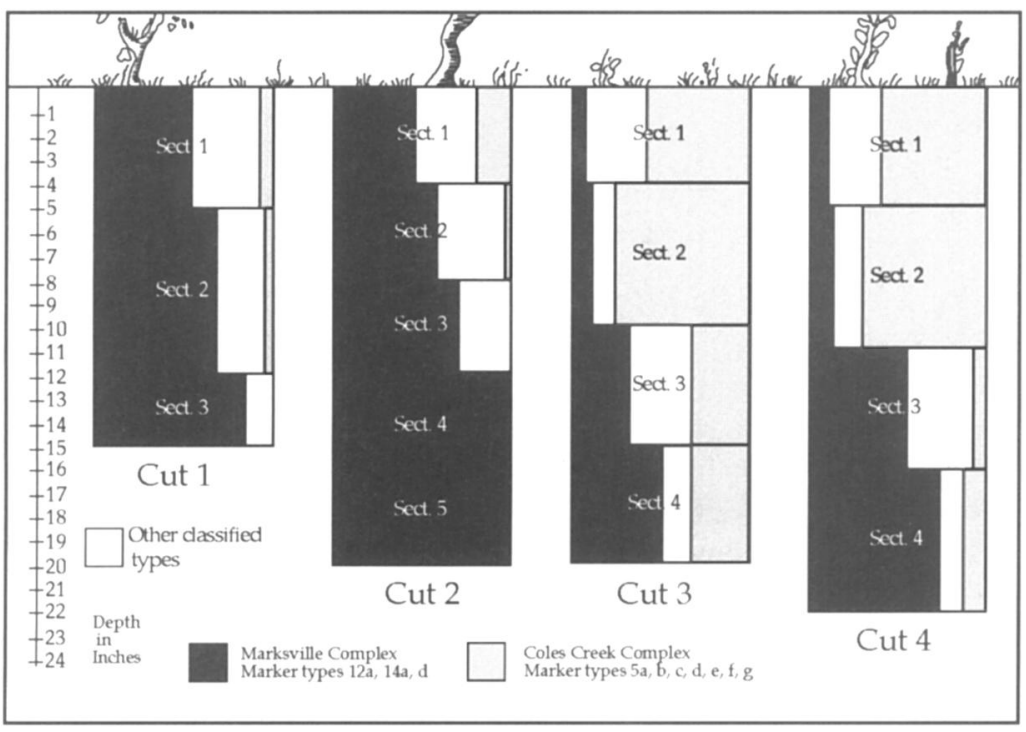

Figure 6. James A. Ford's graph of percentage-stratigraphy data. Note that each column represents a unique horizontal location, different shading indicates different types, and the widths of each set of bars in a row within a column sum to 100 percent (after Ford 1935:22, Figure 9).

periods were "numbered instead of named [to emphasize] the arbitrary nature of the [resulting time] scale."

Rouse then calculated the relative frequencies of eight modes per period across the periods; because the selected modes tended to display unimodal frequency distributions, this, in Rouse's eyes, provided a "statistical validation" of the hypothetical sequence. Finally, he compiled percentage-stratigraphy data for the eight modes with the expectation that "if the postulated sequence were valid ... the frequencies of each of the eight modes should vary from the bottom to the top levels of single middens in the same directions that they vary [through periods in] the [hypothetical] sequence" (Rouse 1939:69-72). The results, Rouse (1939:71) indicated, "seem to substantiate the validity of the postulated sequence."

Thus, Rouse used a combination of analytical techniques to construct, and then another technique to test, a chronological sequence. His diamond graph was meant to show the changing frequencies of modes through the six periods. Rouse $(1939: 84)$ stated that he constructed the graph from his data tables. That this graph is an interpretation is clear from several of its features. First, the data tables have no pottery listed in Period I, yet Rouse's graph indicates pottery is present. Second, the diamonds variously expand and contract within periods, when in fact the data in the tables are presented in such a manner-by period - that any graphed change in frequencies must occur at the boundaries between periods.

None of the three graphs discussed above is a direct reflection of empirical data; rather, the graphs represent what the researchers believed the frequency distribution of types or modes to be through time. Others who produced such graphs (e.g., Beardsley 1948:5; Carter 1941:224; Heizer and Fenenga 1939:392) also tended to use them to present their interpretations rather than as devices by which empirical data might be summarized. For example, Ford $(1949,1952 \mathrm{~b})$ used diamond graphs, but it was in exactly the same manner as his predecessors had done. Ford's graphs had a basis in empirical data, but they were interpretations that diverged to varying degrees from the reality of those data, as Spaulding (1953) did not hesitate to point out (O'Brien and Lyman 1998).

Diamond graphs were widely used by culture historians, but their use was eclipsed by the use of bar graphs, which often were employed in conjunction with both frequency seriation and percentage stratigraphy. This contributed to the confusion of these two distinct analytical techniques. The history of the use of what we are calling bar graphs is complex. It appears to have originated with Ford but was used by Paul Martin 


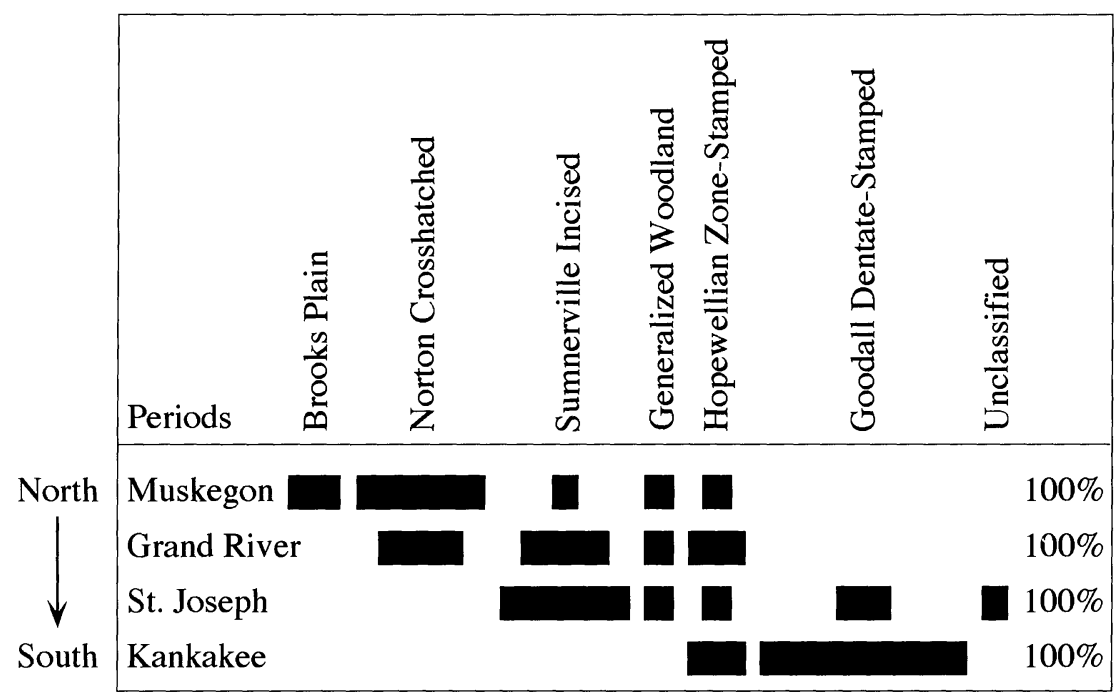

Figure 7. George I. Quimby's seriation based on geographic space. Bar widths in each row sum to 100 percent (after Quimby 1943:547, Figure 2).

and others at virtually the same time. We begin with Ford's work and that of some of his colleagues, and then turn to Martin's efforts.

Working at a small site in Louisiana in 1934, Ford (1935:6) excavated in what we would today call arbitrary levels, the thicknesses of which varied as he attempted to collect from each "an appreciable amount of material." He knew which ceramic types made up various "decoration complexes"-knowledge based in part on the corresponding geographic distributions of those types and the historical distributions of distinct ethnic groups; these were his "complex markers," or "marker types." He plotted the relative frequencies of these marker types, plus other, nondiagnostic types, against their vertical provenience (Figure 6). This was an early version of a bar graph used in the service of percentage stratigraphy. Note that the width of the bars is a graphic representation of data, not an interpretation. Thus, the bars shift widths only at the horizontal boundaries that separate them into vertically discrete units, and their widths always sum to 100 percent within a period and between periods. Ford's use of bar graphs expanded a few years later when he presented nearly all of the percentage-stratigraphy data from an extensively excavated site with such graphs (Ford and Quimby 1945). He did not, however, interdigitate the various excavation units to derive an overall chronology for the site, probably because it appeared to represent what later became known as a "single-component" site. It probably was Ford's graphic method, however, that inspired one of his collaborators to produce the first bar graph that might be thought of as representing a frequency seriation.

In 1942, George Quimby, who had been working with Ford for several years (O'Brien and Lyman 1998), presented a paper to the Michigan Academy of Science, Arts, and Letters that was published the following year. Quimby (1943:543) began his paper by noting that his purpose was "to construct a synthetic chronology as a temporal frame within which to view the ceramic content of a prehistoric Indian culture complex that I have elsewhere called the Goodall focus." He then noted that the geographic distribution of the 10 "components" in the general area of southwestern Michigan known to belong to this focus suggested a north-south trend in the "distribution, frequency, and cultural similarity [of] traits" (Quimby 1943:545). Quimby reasoned that perhaps this geographic trend was also chronological if diffusion were involved. He then ordered the relative frequencies of pottery types using each latitudinally designated area as a "period" and lumping components within each. Thus, the basis of the ordering was geographic location. He presented not only the absolute abundances of each pottery type in tabular form, but also a bar graph, each bar 
segment representing "the percentages of the pottery types by periods" (Quimby 1943:546) and, we might add, by latitude.

Quimby's (1943:547) graph is reproduced here as Figure 7, with the addition of an indication of latitude. Quimby (1943:546) interpreted the graph as indicative of the passage of time when he spoke of the "persistent [occurrence of one type] throughout all four periods" and the "waning" or "declining popularity" of another type. But is the graph a frequency seriation, given that the basis of the ordering was geographic location rather than formal properties of the artifacts? In the strict wording of the definition we provide above, it is not. However, it is close to being such a seriation if one realizes that the graph illustrates a case of what Deetz and Dethlefsen (1965) two decades later termed the "Doppler Effect," at least in-so-far as Quimby was correct to suggest that diffusion was playing a role. In other words, Quimby's graph not only must be considered in the history of graphic techniques for summarizing the changing frequencies of artifact types through time, but it must be considered in the history of frequency seriation. He knew he was monitoring spatial difference, and he presumed he also was measuring temporal difference, given his thoughts about the role of diffusion. Explicit recognition that one had to control for geographic space in order to help ensure that only time was being measured was, at the time Quimby wrote, only then emerging. As Willey (1940:675), for example, noted with regard to Rouse's (1939) Haitian chronology, "age-area implications are a potential factor" influencing the fluctuating frequencies of types and modes.

It is important to remember that Quimby's graph presented empirical data. It was not drawn as an interpretation but rather as a summary rendition of data. In this respect, it aligns with Ford's bar graphs of percentage-stratigraphy data. Ford (1951, 1952b; Ford et al. 1955; Phillips et al. 1951) continued to produce such graphs in the $1950 \mathrm{~s}$, all of them founded on and illustrating in summary fashion percentage-stratigraphy data, much of it interdigitated to produce a master chronology. These graphs were the source of Ford's interpretations of culture history; rarely did he produce a diamond graph as an interpretation (e.g., Ford $1949: 58,1952 b)$. Only a very small portion of one graph produced by Ford is, strictly speaking, a fre- quency seriation, and this was meant to fill a gap in the master chronology produced by interdigitation of percentage-stratigraphy data from the Virú Valley (Ford 1949:47). Curiously, the only major frequency seriation involving Ford's data was done by Bennyhoff (1952), who, much to Ford's (1952a) consternation, ignored the fact that much of Ford's data that Bennyhoff seriated came from superposed contexts. Frequency seriation produced graphs of "more handsome appearance" than Ford's (1952a:250) —and the popularity principle is much more obvious in Bennyhoff's graph than in Ford's-but it violated the temporal implications of superposition.

Martin (1936) initially used broken-stick graphs to report percentage-stratigraphy data, and why he shifted to a form of bar graph within a few years (Martin 1938, 1939) is not clear. Whatever the reason, he did not interdigitate these data because he could detect "no consistent variations or periodic fluctuations" (Martin 1938:276; see also Martin 1939:454). Similarly, a few years later he again used a simple form of bar graph to illustrate the relative frequency of various artifact types from different proveniences of a single site (Martin 1943:245; Martin and Rinaldo 1947:363). Interestingly, the caption of one of these graphs includes the statement "Chart devised by Don Lehmer" (Martin 1943:245). The word "devised" is misleading because to us it implies the graph was Lehmer's innovation, yet Martin had earlier published identical graphs.

After additional years of work and a better understanding of the cultural chronology where he was working, Martin still did not know some of the particular details. He wrote, "In seeking, then, trends within [frequencies of] pottery types and any other significant observations that might accrue from a comprehensive visual presentation of data, we decided to employ a graphic method similar to that used by James A. Ford and others in their studies of archaeology of the southeastern United States (Ford and Willey 1940; Ford and Quimby 1945)" (Martin et al. 1949:196). Before this, the bars denoting relative frequencies in Martin's graphs had been right aligned; now, they were centered in a column, just as Ford's graphs of the early 1940s were. And, not only was Martin et al.'s (1949:192-193) resultant graph a frequency seriation of assemblages of pottery, each from a 


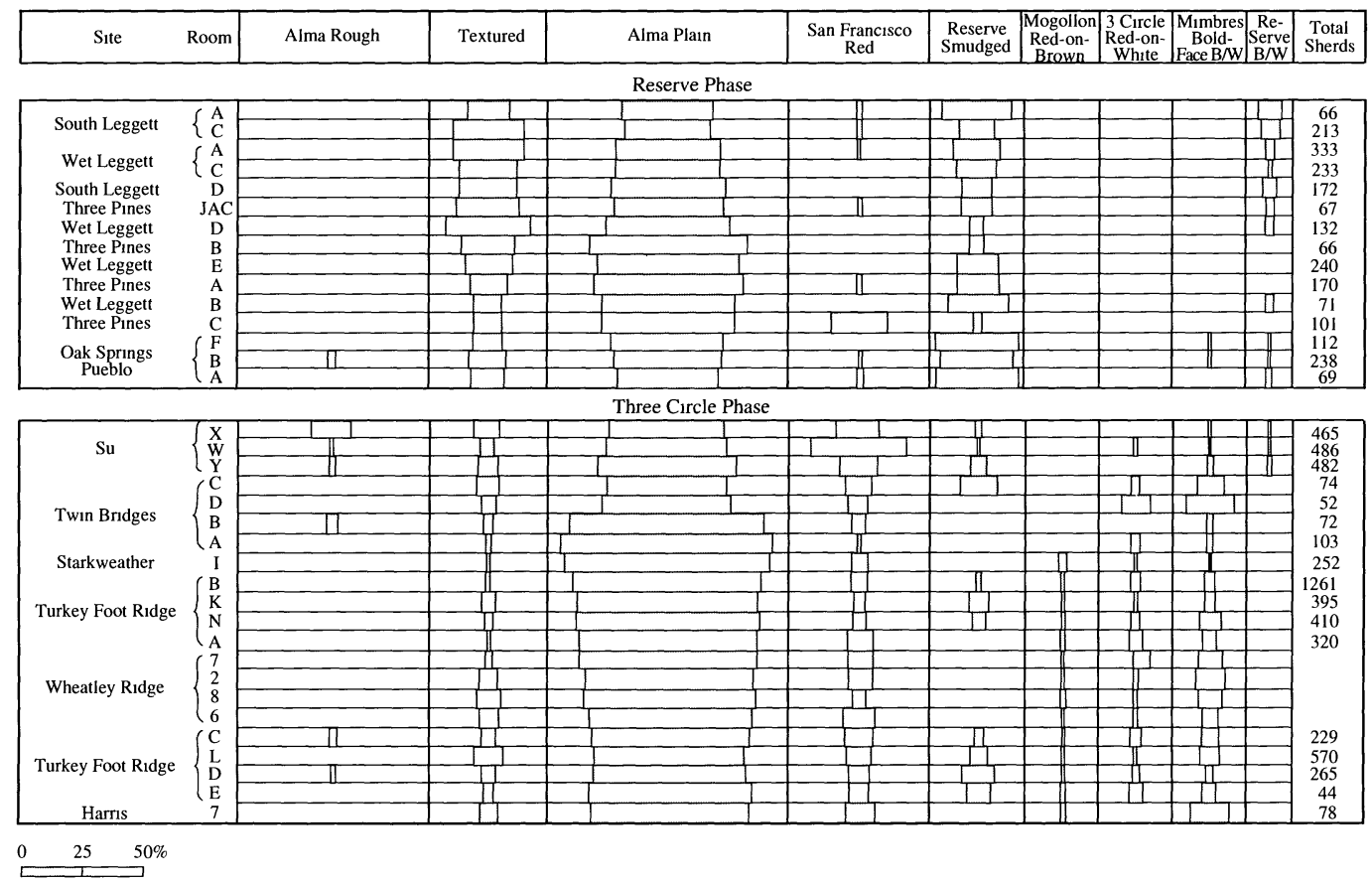

Figure 8. Paul S. Martin and John Rinaldo's frequency seriation. Bar widths in each row sum to 100 percent (after Martin and Rinaldo 1950a:531, Figure 216).

different house floor, he called it that: "What we have attempted... is a seriation of house units based on pottery percentages.... In making the graph no consideration was given to sites, phases, tree-ring dates or other knowledge" (Martin et al. 1949:196-197). After the seriation had been performed, whether the resulting order reflected the passage of time was tested and confirmed by treering dates and stratigraphy.

The frequency seriation rendered as a bar graph by Martin et al. (1949) was modified slightly a year later when Martin and Rinaldo (1950b:372-373) added some new data. A portion of the graph, reproduced here as Figure 8 , was published in a subsequent paper, again with modifications in light of newly acquired data (Martin and Rinaldo 1950a:531). Just prior to the publication of these later two frequency seriations, Rinaldo (1950) published a frequency seriation for materials in a nearby area. His discussion is noteworthy because while it echoes the discussion of Martin et al. (1949), it also adds some details. Ririaldo (1950:94) reported that the technique used "was a variation on a graphic method used by James Ford and others in their studies of archaeology of the southeastern United States (Ford and Willey 1940;
Ford and Quimby 1945)." But he also followed this sentence with the statement "Such a method is not foreign to the Southwest as it is essentially the classical type of seriation that Spier used in his [An] Outline for [a] Chronology of Zuni Ruins. However, in our graph it is represented in a column-wedge type graph similar to that used by Haury and Sayles in illustrating relative frequencies of artifact types through time at Snaketown (Gladwin et al. 1937)." Rinaldo was correct; his seriation (and those of Martin) was founded on the same-popularity-principle as Spier's, a principle that began with Kroeber and Nelson. He also correctly noted that the graphic technique had been borrowed. But Rinaldo was incorrect in another respect; what Sayles did was not at all similar to what Kroeber, Spier, or Rinaldo and Martin did, either analytically or conceptually.

\section{Discussion}

There were, to be sure, variations in the graphic techniques used to display what had been observed. Webb and DeJarnette (1942) plotted absolute frequencies of various artifact categories against arbitrary levels (depth) in a histogram, the bars being right aligned. Beals et al. (1945) used 
percentage stratigraphy to develop a chronology, and they drew a new form of broken-stick graph with (1) the lines denoting frequency drawn so as not to cross one another and (2) the cumulative areas under them summing to 100 percent; they drew bar graphs; and they phyletically seriated design elements of their pottery. Some archaeologists continued to use tables of numbers to present percentage-stratigraphy data (e.g., Bird 1943; Drucker 1943a, 1943b; Ekholm 1944; Rowe 1944). As indicated above, Martin and Rinaldo did true seriations without the aid of superposition and without interdigitation to help order collections. They and their associates continued to do so through the 1950s, producing numerous bar graphs like those in Figure 8 (Bluhm 1957:36; Martin et al. 1956:138; Martin et al. 1957:91; Rinaldo 1959:280). But some who published in the series where these papers appeared-Fieldiana: Anthropology-used similar graphs to illustrate percentage-stratigraphy data and to create a chronology rather than to test one, referring to the data presented in those graphs as "seriation data" (Spoehr 1957:124) and the analytical technique used as "seriation of sherd units from refuse deposits" (Collier 1955:101).

Ritchie and MacNeish (1949:99) knew the basic sequence of pre-Iroquoian "cultures" in New York based on "previous stratigraphic evidence." They then used frequency seriation-what they referred to as "the actual process of seriation"- to arrange various assemblages within each of those cultures, noting that the basic assumption of the procedure was that "closely comparable [relative frequency] values [of types] indicated a corresponding proximity in time and space" (Ritchie and MacNeish 1949:99). They also noted that "the materials are arranged in overlapping or interdigitating sequence" (Ritchie and MacNeish 1949:98), but they did not use superposition to help with the integration of the various assemblages. Their graphs consist of right-aligned bars, the widths of which denote the relative frequencies of types. That same year, Willey (1949) published his interdigitated percentage-stratigraphy data (Figure 2). The simultaneous publication of these two reports in which the term "interdigitation" was used probably contributed to its abandonment, because in Ritchie and MacNeish's case it was part of the analytical process of frequency seriation, whereas in
Willey's case it was part of the process of integrating percentage-stratigraphy data.

In the early 1950s, Strong and Evans (1952) published their ceramic chronology for the Virú Valley, which was based on interdigitated percentage-stratigraphy data. The caption associated with their figure reads, in part, "Correlation chart of the ceramic stratigraphy of ... sherds" (Strong and Evans 1952). This graph is very similar in appearance and identical in the way it was constructed to Ford's (1949) earlier ones for the Virú Valley. Collier's (1955:106) bar graphs of interdigitated percentage-stratigraphy data appeared a few years later, at the same time that Evans's (1955:82) bar graphs of interdigitated percentage-stratigraphy data did. Both authors smoothed the bar graphs with dotted lines, just as Ford (1949, 1951, 1952b) had done earlier, but only Ford's graphs for the Southeast were the subject of Spaulding's (1953) wrath. Brainerd (1951) and Robinson (1951) had just published their discussions of a statistical technique for sorting collections, and Spaulding thought such a technique was much more objective and would produce more accurate results than Ford's procedure of visually sorting bars of various widths. Yet researchers continued to follow Ford's procedure.

Terminological confusion was rampant as a result. Evans (1955:82), for example, used interdigitated percentage-stratigraphy data from various sites to derive an overall sequence, but he then used that sequence to help determine the direction of time's flow by employing frequency seriation to sort and arrange collections from other sites. As he noted, "Good and meaningful seriation cannot be attained without some method that will indicate absolutely which is the top and which is the bottom of the seriated sequence" (Evans 1955:77). He used percentage-stratigraphy data, just as Spier (1917a, 1917b) had done 40 years earlier, to determine which end was up. His bar graphs of seriated and percentage-stratigraphy data were, however, so similar in appearance that confusion over which was which was a predictable result. A few years later, Ford (1962) himself categorized Evans's work as frequency seriation only. Meggers and Evans (1957) and Evans and Meggers (1960) published numerous bar graphs, some representing frequency seriations, some interdigitated percentage-stratigraphy data; virtually all were termed "seriations." 
We suggest that sloppy use of terms in conjunction with similarities of graphs depicting changing frequencies of artifact types contributed to (1) the confusion of frequency seriation and interdigitated percentage-stratigraphy data, and (2) the modern myth that James Ford regularly seriated artifact collections and other misconceptions. We believe Ford himself contributed to both. In his retrospective overview, Ford (1962:5) indicated

\begin{abstract}
In the second decade of this century the idea became current that quantities of [types] of material found should be listed, and "Percentage Stratigraphy" almost became a fad. Proportions were graphed as well as tabulated, but there was as yet no idea that these frequencies might be a reflection of cultural phenomena. "Percentage Stratigraphy" was looked upon as somewhat inferior to clear-cut superposition [which consisted of] finding one culture or cultural phase superimposed over another with clear differentiation between the two.

The use of popularity curves of types, and the construction of chronologies by discovering the frequency patterns formed by types, developed in the 1930's and has become increasingly popular, particularly in the work of American archaeologists.
\end{abstract}

What Ford meant by the term "percentage stratigraphy" is similar to the way in which we have defined it. Ford (1962:4) also correctly attributed the introduction of frequency seriation in Americanist archaeology to Kroeber, but he incorrectly attributed the invention of the technique by Kroeber to the influence of Petrie and Uhle. More importantly in the present context, Ford (1962) failed to keep the distinction between percentage stratigraphy and frequency seriation straight in his history of the techniques. Thus, he incorrectly linked his own early work (Ford 1936) with Spier's (1917b); as we have argued here, what Ford did was to sort surface collections into periods based on index fossils-periods founded on percentagestratigraphy data-and he did not order those assemblages within the periods (O'Brien and Lyman 1998). Spier (1917a, 1917b) used percentage-stratigraphy data to confirm the temporal significance of his frequency seriations of surface collections. Ford (1962) also incorrectly categorized George Vaillant's (e.g., 1930, 1931) work as involving percentage stratigraphy. In our view (Lyman et al. 1997), Vaillant's work was founded on index fossils and ceramic stratigraphy; he pre- sented frequencies of types after the basic sequence had been worked out, but merely to show the abundances of various types within particular periods.

Ford (1949, 1951, 1952b; Ford and Quimby 1945; Ford and Willey 1940; Phillips et al. 1951) relied heavily on percentage-stratigraphy data and only rarely on frequency seriation alone to construct a chronology. To attribute to him the use of frequency seriation is incorrect; to attribute to him the popularization of it as an analytical technique is more correct (e.g., Marquardt 1978:260), but the popularity was the result of his clearly readable percentage-stratigraphy graphs, not his use of the technique of frequency seriation. The waxing and waning of a type-its popularity - was clearly visible in the bar graphs Ford pioneered. Those graphs were empirical, unlike the diamond graphs of Olson (1930), Sayles (1937), Rouse (1939), and others. As Bennyhoff (1952:231) indicated regarding the chronology for the Virú Valley, Ford's "ingenious graphic presentations of data are of general interest to archaeologists and can be expected to influence students of prehistory working in fields other than Peru." The references cited here indicate that Bennyhoff's prediction came true, but not without the cost of an extremely confusing terminology.

\section{Conclusion}

In a recently published encyclopedia (Stone 1996:634) of archaeology, seriation is described as follows:

Seriation includes a number of relative dating techniques ... based on a reconstruction of typological or stylistic changes in material culture through time....

To construct the seriation for an area, stratified sites usually are examined. By examining typological or stylistic shifts from the different strata, these changes can be placed in a relative chronological order. Once the seriation of an area is unraveled at a single or several stratified sites, it can be used to place other sites into a regional temporal ordering through [artifact] cross-dating.

As should be clear from our discussion here, we find such a characterization of seriation not only to be ambiguous but also incorrect. It conflates several distinct analytical techniques, thereby leading to confusion regarding the history of the discipline 
and how particular chronological problems might be solved.

In our view, Martin and Rinaldo should be recognized for their innovative frequency seriations, whereas Ford should be credited for his innovative graphic technique, but noting that what Ford was graphing were percentage-stratigraphy data. That the graphs of Ford and of Martin and Rinaldo had very similar appearances and displayed the popularity principle in concise and clearly perceptible fashion no doubt contributed to the confusion among the techniques of frequency seriation, percentage stratigraphy, and interdigitation. Focusing only on the overall appearance of such graphs misses the critical distinction of the principles used to construct them.

To be sure, frequency seriation, percentage stratigraphy, and interdigitation are interrelated through their common adherence to the popularity principle - that is, that historical types will have a continuous distribution through time and display a single waxing and waning of each type's popularity. Otherwise, they are distinct. Frequency seriation, on the one hand, is not phyletic seriation. It arranges collections on the basis of attributes internal to the collections, specifically, the frequencies of types, which phyletic seriation ignores. Some attribute external to the collections such as superposition or another source of chronological data must be called on to determine the direction of time's flow. On the other hand, percentage stratigraphy in conjunction with interdigitation arranges collections not only on the basis of attributes internal to the collections - type frequencies-but also simultaneously uses attributes external to the collections - their superposed positions-to aid in the arrangement process. It precludes the necessity of determining the direction of time's flow after the arrangement is completed because that is already known. That the results of both procedures can be presented in similar form graphically should no longer cause us to think either that the analytical steps in both are identical or that creating an ordering based on frequency seriation involves the use of superposition as a principle of arrangement.

Acknowledgments. We thank George Cowgill, E. J. O'Brien, Lynne Goldstein, and three anonymous reviewers for their many editorial suggestions and Dan Glover for producing the illustrations.

\section{References Cited}

Amsden, C. A.

1931 Black-on-White Ware. In The Pottery of Pecos, vol. 1, by A. V. Kidder, pp. 17-72. Papers of the Southwestern Expedition, Phillips Academy No. 5. Yale University Press, New Haven, Connecticut.

Beals, R. L., G. W. Brainerd, and W. Smith

1945 Archaeological Studies in Northeast Arizona. Publications in American Archaeology and Ethnology Vol. 44, Pt. 1. University of California, Berkeley.

Beardsley, R. K.

1948 Culture Sequences in Central California Archaeology. American Antiquity 14:1-28.

Bennyhoff, J. A.

1952 The Virú Valley Sequence: A Critical Review. American Antiquity 17:231-249.

Binford, L. R.

1968 Archeological Perspectives. In New Perspectives in Archeology, edited by S. R. Binford and L. R. Binford, pp. 5-32. Aldine, Chicago.

Bird, J. B.

1943 Excavations in Northern Chile. Anthropological Papers Vol. 38 No. 4. American Museum of Natural History, New York.

Bluhm, E. A.

1957 The Sawmill Site: A Reserve Phase Village, Pine Lawn Valley, Western New Mexico. Fieldiana: Anthropology Vol. 47 No. 1. Field Museum of Natural History, Chicago. Brainerd, G. W.

1951 The Place of Chronological Ordering in Archaeological Analysis. American Antiquity 16:301-313.

Braun, D. P.

1985 Absolute Seriation: A Time-Series Approach. In For Concordance in Archaeological Analysis, edited by C. Carr, pp. 509-539. Westport, Kansas City.

Browman, D. L., and D. R. Givens

1996 Stratigraphic Excavation: The First "New Archaeology." American Anthropologist 98:80-95.

Carter, G. F.

1941 Archaeological Notes on a Midden at Point Sal. American Antiquity 6:214-226.

Collier, D.

1955 Cultural Chronology and Change as Reflected in the Ceramics of the Virú Valley, Peru. Fieldiana: Anthropology Vol. 43. Field Museum of Natural History, Chicago.

Collier, D., and J. V. Murra

1943 Survey and Excavations in Southern Ecuador. Fieldiana: Anthropology Vol. 35. Field Museum of Natural History, Chicago.

Colton, H. S., and L. L. Hargrave

1937 Handbook of Northern Arizona Pottery Wares. Bulletin No. 11. Museum of Northern Arizona, Flagstaff.

Cowgill, G. L.

1972 Models, Methods and Techniques for Seriation. In Models in Archaeology, edited by D. L. Clarke, pp. 381-424. Methuen, London.

Deetz, J.

1970 Archeology as a Social Science. In Current Directions in Anthropology: A Special Issue, edited by A. Fischer, pp. 115-125. Bulletin 3(3)(2). American Anthropological Association, Washington, D.C.

Deetz, J., and E. Dethlefsen

1965 The Doppler Effect and Archaeology: A Consideration of the Spatial Aspects of Seriation. 
Southwestern Journal of Anthropology 21:196-206.

Drucker, P.

1943a Ceramic Sequences at Tres Zapotes, Veracruz, Mexico. Bureau of American Ethnology Bulletin No. 140. Smithsonian Institution, Washington, D.C.

1943b Ceramic Stratigraphy at Cerro de las Mesas, Veracruz, Mexico. Bureau of American Ethnology Bulletin No. 141. Smithsonian Institution, Washington, D.C.

1981 Obituary: Ronald Leroy Olson. American Anthropologist 83:605-607.

Dunnell, R. C.

1970 Seriation Method and Its Evaluation. American Antiquity 35:305-319.

1978 Style and Function: A Fundamental Dichotomy. American Antiquity 43:192-202.

1986 Methodological Issues in Americanist Artifact Classification. In Advances in Archaeological Method and Theory, vol. 9, edited by M. B. Schiffer, pp. 149-207. Academic Press, Orlando, Florida.

Dutton, B. P.

1938 Leyit Kin, a Small House Ruin, Chaco Canyon, New Mexico. Monograph Series No. 7, Vol. 1. School of American Research, Santa Fe, and University of New Mexico Press, Albuquerque.

Ekholm, G. F.

1944 Excavations at Tampico and Panuco in the Huasteca, Mexico. Anthropological Papers Vol. 38 Pt. 5. American Museum of Natural History, New York.

Evans, $\mathrm{C}$.

1955 A Ceramic Study of Virginia Archeology. Bureau of American Ethnology Bulletin No. 160. Smithsonian Institution, Washington, D.C.

Evans, C., and B. J. Meggers

1960 Archeological Investigations in British Guiana. Bureau of American Ethnology Bulletin No. 177. Smithsonian Institution, Washington, D.C.

Evans, J.

1850 On the Date of British Coins. The Numismatic Chronicle and Journal of the Numismatic Society 12(4):127-137.

Ford, J. A.

1935 Ceramic Decoration Sequence at an Old Indian Village Site, near Sicily Island, Louisiana. Anthropological Study No. 1. Louisiana State Geological Survey, Department of Conservation, New Orleans.

1936 Analysis of Village Site Collections from Louisiana and Mississippi. Anthropological Study No. 2. Louisiana State Geological Survey, Department of Conservation, New Orleans.

1938 A Chronological Method Applicable to the Southeast. American Antiquity 3:260-264.

1949 Cultural Dating of Prehistoric Sites in Virú Valley, Peru. Anthropological Papers Vol. 43 Pt. 1. American Museum of Natural History, New York.

1951 Greenhouse: A Troyville-Coles Creek Period Site in Avoyelles Parish, Louisiana. Anthropological Papers Vol. 44 Pt. 1. American Museum of Natural History, New York.

1952a Reply to "The Virú Valley Sequence: A Critical Review." American Antiquity 17:250.

1952b Measurements of Some Prehistoric Design Developments in the Southeastern States. Anthropological Papers Vol. 44 Pt. 3. American Museum of Natural History, New York.

1962 A Quantitative Method for Deriving Cultural Chronology. Technical Bulletin No. 1. Pan American
Union, Washington, D.C.

Ford, J. A., P. Phillips, and W. G. Haag

1955 The Jaketown Site in West-Central Mississippi.

Anthropological Papers Vol. 46 Pt. 1. American Museum of Natural History, New York.

Ford, J. A., and G. I. Quimby, Jr.

1945 The Tchefuncte Culture, An Early Occupation of the Lower Mississippi Valley. Memoirs No. 2. Society for American Archaeology, Washington, D.C.

Ford, J. A., and G. R. Willey

1940 Crooks Site, a Marksville Period Burial Mound in La Salle Parish, Louisiana. Anthropological Study No. 3. Louisiana State Geological Survey, Department of Conservation, New Orleans.

Gamio, M.

1913 Arqueologia de Atzcapotzalco, D.F., Mexico. Proceedings of the Eighteenth International Congress of Americanists, pp. 180-187. London.

Givens, D. R.

1992 Alfred Vincent Kidder and the Development of Americanist Archaeology. University of New Mexico Press, Albuquerque.

Gladwin, H. S., E. W. Haury, E. B. Sayles, and N. Gladwin

1937 Excavations at Snaketown: I. Material Culture. Medallion Papers No. 25. Gila Pueblo, Globe, Arizona.

Gorenstein, S.

1977 History of American Archaeology. In Perspectives on Anthropology 1976, edited by A. F. C. Wallace, J. L. Angel, R. Fox, S. McLendon, R. Sady, and R. Sharer, pp. 86-100. Special Publication No. 10. American Anthropological Association, Washington, D.C.

Haury, E. W.

1937 Stratigraphy. In Excavations at Snaketown: I. Material Culture, by H. S. Gladwin, E. W. Haury, E. B. Sayles, and N. Gladwin, pp. 19-35. Medallion Papers No. 25. Gila Pueblo, Globe, Arizona.

Hawley, F. M.

1934 The Significance of the Dated Prehistory of Chetro Ketl. Monograph Series Vol. 1(1). University of New Mexico, Albuquerque.

Heizer, R. F. (editor)

1959 The Archaeologist at Work. Harper, New York.

Heizer, R. F., and F. Fenenga

1939 Archaeological Horizons in Central California. American Anthropologist 1:378-399.

Hester, T. R., R. F. Heizer, and J. A. Graham

1975 Field Methods in Archaeology. 6th ed. Mayfield, Palo Alto, California.

Holmes, W. H.

1885 Evidences of the Antiquity of Man on the Site of the City of Mexico. Transactions of the Anthropological Society of Washington 3:68-81.

Kidder, A. V.

1915 Pottery of the Pajarito Plateau and of Some Adjacent Regions in New Mexico. Memoir No. 2, pp. 407-462. American Anthropological Association, Washington, D.C.

1916 Archeological Explorations at Pecos, New Mexico. Proceedings of the National Academy of Sciences 2:119-123. Washington, D.C.

1917 A Design-Sequence from New Mexico. Proceedings of the National Academy of Sciences 3:369-370. Washington, D.C.

1919 Review of An Outline for a Chronology of Zuñi Ruins; Notes on Some Little Colorado Ruins; Ruins in the White Mountains, Arizona, by L. Spier. American Anthropologist 21:296-301. 
1924 An Introduction to the Study of Southwestern Archaeology, with a Preliminary Account of the Excavations at Pecos. Yale University Press, New Haven, Connecticut.

1931 The Pottery of Pecos, vol. 1. Yale University Press, New Haven, Connecticut.

1936 Introduction. In The Pottery of Pecos, vol. 2, by A. V. Kidder and A. O. Shepard, pp. xvii-xxxi. Yale University Press, New Haven, Connecticut.

Kidder, M. A., and A. V. Kidder

1917 Notes on the Pottery of Pecos. American Anthropologist 19:325-360.

Kniffen, F. B.

1938 The Indian Mounds of Iberville Parish. In Reports on the Geology of Iberville and Ascension Parishes, edited by H. V. Howe, pp. 189-207. Geological Bulletin No. 13. Louisiana Geological Survey, New Orleans.

Kroeber, A. L.

1916a Zuñi Culture Sequences. Proceedings of the National Academy of Sciences 2:42-45. Washington, D.C.

1916b Zuñi Potsherds. Anthropological Papers Vol. 18 Pt. 1. American Museum of Natural History, New York.

1919 On the Principle of Order in Civilization as Exemplified by Changes of Fashion. American Anthropologist 21:235-263.

1925a Archaic Culture Horizons in the Valley of Mexico. Publications in American Archaeology and Ethnology Vol. 17 Pt. 7. University of California, Berkeley.

1925b Handbook of the Indians of California. Bureau of American Ethnology Bulletin No. 78. Smithsonian Institution, Washington, D.C.

1927 Coast and Highland in Prehistoric Peru. American Anthropologist 29:625-653.

Kroeber, A. L., and W. D. Strong

1924 The Uhle Pottery Collections from Ica. Publications in American Archaeology and Ethnology Vol. 21 Pt. 3. University of California, Berkeley.

Lyman, R. L., and M. J. O'Brien

1998 Americanist Stratigraphic Excavation and the Measurement of Culture Change. Journal of Archaeological Method and Theory, in press.

Lyman, R. L., M. J. O'Brien, and R. C. Dunnell

1997 The Rise and Fall of Culture History. Plenum, New York.

Marquardt, W. H.

1978 Advances in Archaeological Seriation. In Advances in Archaeological Method and Theory, vol. 1, edited by M. B. Schiffer, pp. 257-314. Academic Press, New York.

Martin, P. S.

1936 Lowry Ruin in Southwestern Colorado. Fieldiana: Anthropology Vol. 23, Pt. 1. Field Museum of Natural History, Chicago.

1938 Archaeological Work in the Ackmen-Lowry Area, Southwestern Colorado, 1937. Fieldiana: Anthropology Vol. 23 Pt. 2. Field Museum of Natural History, Chicago. 1939 Modified Basket Maker Sites, Ackmen-Lowry Area, Southwestern Colorado, 1938. Fieldiana: Anthropology Vol. 23 Pt. 3. Field Museum of Natural History, Chicago.

1943 The SU site: Excavations at a Mogollon Village, Western New Mexico, Second Season, 1941. Fieldiana: Anthropology Vol. 32 Pt. 2. Field Museum of Natural History, Chicago.

Martin, P. S., and J. B. Rinaldo

1947 The SU site: Excavations at a Mogollon Village, Western New Mexico, Third Season, 1946. Fieldiana: Anthropology Vol. 32 Pt. 3. Field Museum of Natural History, Chicago. 1950a Sites of the Reserve Phase, Pine Lawn Valley, Western New Mexico. Fieldiana: Anthropology Vol. $38 \mathrm{Pt}$. 3. Field Museum of Natural History, Chicago.

1950b Turkey Foot Ridge Site: A Mogollon Village, Pine Lawn Valley, Western New Mexico. Fieldiana: Anthropology Vol. 38 Pt. 2. Field Museum of Natural History, Chicago.

Martin, P. S., J. B. Rinaldo, and E. Antevs

1949 Cochise and Mogollon Sites, Pine Lawn Valley, Western New Mexico. Fieldiana: Anthropology Vol. $38 \mathrm{Pt}$.

1. Field Museum of Natural History Chicago.

Martin, P. S., J. B. Rinaldo, and E. R. Barter

1957 Late Mogollon Communities: Four Sites of the Tularosa Phase, Western New Mexico. Fieldiana: Anthropology Vol. 49 Pt. 1. Field Museum of Natural History, Chicago.

Martin, P. S., J. B. Rinaldo, E. A. Bluhm, and H. C. Cutler

1956 Higgins Flat Pueblo, Western New Mexico. Fieldiana: Anthropology Vol. 45. Field Museum of Natural History, Chicago.

McGregor, J. C.

1941 Southwestern Archaeology. John Wiley, New York.

1965 Southwestern Archaeology, 2nd ed. University of Illinois Press, Urbana.

Meggers, B. J., and C. Evans

1957 Archeological Investigations at the Mouth of the Amazon. Bureau of American Ethnology Bulletin No. 167. Smithsonian Institution, Washington, D.C.

Morgan, L. H.

1877 Ancient Society. Holt, New York.

Nelson, N. C.

1916 Chronology of the Tano Ruins, New Mexico. American Anthropologist 18:159-180.

1919 Human Culture. Natural History 19:131-140.

1920 Notes on Pueblo Bonito. Anthropological Papers Vol. 27, pp. 381-390. American Museum of Natural History, New York

Nesbitt, P. H.

1938 Starkweather Ruin: A Mogollon-Pueblo Site in the Upper Gila Area of New Mexico, and Affiliative Aspects of the Mogollon Culture. Bulletin No. 6. Logan Museum, Beloit, Wisconsin.

O'Brien, M. J., and R. L. Lyman

1998 Measuring the Flow of Time: James A. Ford and the Growth of Americanist Archaeology. University of Missouri Press, Columbia.

Olson, R. L.

1930 Chumash Prehistory. Publications in American Archaeology and Ethnology Vol. 28 Pt. 1. University of California, Berkeley.

Petrie, W. M. F.

1899 Sequences in Prehistoric Remains. Journal of the Royal Anthropological Institute of Great Britain and Ireland 29:295-301.

1901 Diospolis Parva. Memoir No. 20. Egypt Exploration Fund, London.

Phillips, $\mathrm{P}$

1951 Reviews of Archeology of the Florida Gulf Coast, by G. R. Willey, and of The Florida Indian and His Neighbors, edited by J. W. Griffin. American Anthropologist 53:108-112

Phillips, P., J. A. Ford, and J. B. Griffin

1951 Archaeological Survey in the Lower Mississippi Valley, 1940-1947. Papers of the Peabody Museum of American Archaeology and Ethnology Vol. 25. Harvard University, Cambridge, Massachusetts.

Pitt-Rivers, A. L.-F.

1875 On the Principles of Classification Adopted in the 
Arrangement of His Anthropological Collection, Now Exhibited in the Bethnal Green Museum. Journal of the Anthropological Institute of Great Britain and Ireland 4:293-308

Plog, F. T

1973 Diachronic Anthropology. In Research and Theory in Current Archeology, edited by C. L. Redman, pp. 181-198. John Wiley, New York.

Praetzellis, A.

1993 The Limits of Arbitrary Excavation. In Practices of Archaeological Stratigraphy, edited by E. C. Harris, M. R. Brown III, and G. J. Brown, pp. 68-86. Academic Press, London.

Quimby, G. I.

1943 The Ceramic Sequence within the Goodall Focus. Papers of the Michigan Academy of Science, Arts and Letters 28:543-548. Ann Arbor.

Reiter, P.

1938 The Jemez Pueblo of Unshagi, New Mexico. Monograph Series 1(5). University of New Mexico, Albuquerque

Rinaldo, J. B.

1950 An Analysis of Culture Change in the Ackmen-Lowry Area. Fieldiana: Anthropology Vol. 36 Pt. 5. Field Museum of Natural History, Chicago.

1959 Foote Canyon Pueblo, Eastern Arizona. Fieldiana: Anthropology Vol. 49 Pt. 2. Field Museum of Natural History, Chicago.

Ritchie, W. A., and R. S. MacNeish

1949 The Pre-Iroquoian Pottery of New York State. American Antiquity 15:97-124.

Robinson, W. S.

1951 A Method for Chronologically Ordering Archaeological Deposits. American Antiquity 16:293-301.

Rouse, I. B.

1939 Prehistory in Haiti: A Study in Method. Publications in Anthropology No. 21. Yale University, New Haven, Connecticut.

1967 Seriation in Archaeology. In American Historical Anthropology: Essays in Honor of Leslie Spier, edited by C. L. Riley and W. W. Taylor, pp. 153-195. Southern Illinois University Press, Carbondale.

Rowe, J. H.

1944 An Introduction to the Archaeology of Cuzco. Papers of the Peabody Museum of American Archaeology and Ethnology Vol. 27 No. 2. Harvard University, Cambridge, Massachusetts.

1961 Stratigraphy and Seriation. American Antiquity 26:324-330

Sapir, E.

1916 Time Perspective in Aboriginal American Culture, A Study in Method. Memoir No. 90. Canada Department of Mines, Geological Survey, Ottawa.

Sayles, E. B.

1937 Stone: Implements and Bowls. In Excavations at Snaketown: I. Material Culture, by H. S. Gladwin, E. W. Haury, E. B. Sayles, and N. Gladwin, pp. 101-120. Medallion Papers No. 25. Gila Pueblo, Globe, Arizona.

Schmidt, E. F.

1928 Time-Relations of Prehistoric Pottery Types in Southern Arizona. Anthropological Papers Vol. 30 Pt. 5. American Museum of Natural History, New York.

Spaulding, A. C.

1953 Review of Measurements of Some Prehistoric Design Developments in the Southeastern States, by J. A. Ford. American Anthropologist 55:588-591.
Spier, L.

1916 New Data on the Trenton Argillite Culture. American Anthropologist 18:181-189.

1917a An Outline for a Chronology of Zuñi Ruins. Anthropological Papers Vol. 18 Pt. 3. American Museum of Natural History, New York.

1917b Zuñi Chronology. Proceedings of the National Academy of Sciences 3:280-283. Washington, D.C.

1918 Notes on Some Little Colorado Ruins. Anthropological Papers Vol. 18 Pt. 4. American Museum of Natural History, New York.

1919 Ruins in the White Mountains, Arizona. Anthropological Papers Vol. 18 Pt. 5. American Museum of Natural History, New York.

1931 N. C. Nelson's Stratigraphic Technique in the Reconstruction of Prehistoric Sequences in Southwestern America. In Methods in Social Science, edited by S. A. Rice, pp. 275-283. University of Chicago Press, Chicago. Spoehr, A.

1957 Marianas Prehistory: Archaeological Survey and Excavations on Saipan, Tinian and Rota. Fieldiana Anthropology Vol. 48. Field Museum of Natural History, Chicago.

Stein, J. K.

1990 Archaeological Stratigraphy. In Archaeological Geology of North America, edited by N. P. Lasca and J. Donahue, pp. 513-523. Centennial Special Vol. 4. Geological Society of America, Boulder, Colorado.

Stewart, O. C.

1980 Memorial to Ronald L. Olson (1895-1979). Journal of California and Great Basin Anthropology 2:162-164

Stone, $\mathrm{T}$.

1996 Seriation. In The Oxford Companion to Archaeology, edited by B. M. Fagan, pp. 634-635. Oxford University Press, New York.

Strong, W. D.

1925 The Uhle Pottery Collections from Ancon. Publications in American Archaeology and Ethnology Vol. 21 Pt. 4. University of California, Berkeley.

Strong, W. D., and C. Evans, Jr.

1952 Cultural Stratigraphy in the Virú Valley, Northern Peru. Columbia University Press, New York.

Taylor, W. W.

1963 Leslie Spier, 1893-1961. American Antiquity 28:379-381.

Teltser, P. A.

1995 Culture History, Evolutionary Theory, and Frequency Seriation. In Evolutionary Archaeology: Methodological Issues, edited by P. A. Teltser, pp. 51-68. University of Arizona Press, Tucson.

Trigger, B. G

1989 A History of Archaeological Thought. Cambridge University Press, Cambridge.

Uhle, $\mathrm{M}$

1902 Types of Culture in Peru. American Anthropologist 4:753-759.

1903 Pachacamac. University of Pennsylvania Press, Philadelphia.

Vaillant, G. C.

1930 Excavations at Zacatenco. Anthropological Papers Vol. 32 Pt. 1. American Museum of Natural History, New York.

1931 Excavations at Ticoman. Anthropological Papers Vol. 32 Pt. 2. American Museum of Natural History, New York.

Watson, P. J.

1990 Trend and Tradition in Southeastern Archaeology. Southeastern Archaeology:43-54. 
Webb, W. S., and D. L. DeJarnette

1942 An Archaeological Survey of Pickwick Basin in the Adjacent Portions of the States of Alabama, Mississippi, and Tennessee. Bureau of American Ethnology Bulletin No. 129. Smithsonian Institution, Washington, D.C.

Wheat, J. B., J. C. Gifford, and W. W. Wasley

1958 Ceramic Variety, Type Cluster, and Ceramic System in Southwestern Pottery Analysis. American Antiquity $24: 34-47$

Willey, G. R.

1939 Ceramic Stratigraphy in a Georgia Village Site. American Antiquity 5:140-147.

1940 Review of Prehistory in Haiti: A Study in Method, by I. Rouse. American Anthropologist 42:673-675.

1949 Archeology of the Florida Gulf Coast. Smithsonian Miscellaneous Collections 113. Smithsonian Institution, Washington, D.C.

1953 Prehistoric Settlement Patterns in the Virú Valley, Peru. Bureau of American Ethnology Bulletin No. 155. Smithsonian Institution, Washington, D.C.
1968 One Hundred Years of American Archaeology. In One Hundred Years of Anthropology, edited by J. O. Brew, pp. 26-53. Harvard University Press, Cambridge, Massachusetts.

Willey, G. R., and J. A. Sabloff

1993 A History of American Archaeology. 3rd ed. Freeman, New York.

Wissler, C.

1916a The Application of Statistical Methods to the Data on the Trenton Argillite Culture. American Anthropologist 18:190-197.

1916b The Genetic Relations of Certain Forms in American Aboriginal Art. Proceedings of the National Academy of Sciences 2:224-226. Washington, D.C.

Received June 20, 1997; accepted September 15, 1997; revised October 28, 1997. 